\title{
High-performance stretchable resistive memories using donor-acceptor block copolymers with fluorene rods and pendent isoindigo coils
}

\author{
Jau-Tzeng Wang ${ }^{1}$, Kengo Saito ${ }^{2}$, Hung-Chin $\mathrm{Wu}^{1}$, Han-Sheng Sun ${ }^{1}$, Chih-Chien Hung ${ }^{3}$, Yougen Chen ${ }^{4}$, \\ Takuya Isono ${ }^{4}$, Toyoji Kakuchi ${ }^{4}$, Toshifumi Satoh ${ }^{4}$ and Wen-Chang Chen ${ }^{1,3}$
}

Diblock copolymers consisting of electron-donating poly[2,7-(9,9-dihexylfluorene)] (PF) rods and electron-withdrawing poly (pendent isoindigo) (Piso) coils were designed and synthesized through a click reaction. The electronic properties and interchain organization of the copolymers could be tuned by varying the PF/Piso ratio $\left(\mathrm{PF}_{14}-b\right.$-Pison $n(n=10,20,60$ and 100)). The highest occupied molecular orbital and lowest unoccupied molecular orbital energy levels of the studied polymers were progressively reduced as the length of Piso increased, affecting the charge trapping and intramolecular charge transfer environment between PF and Piso domains. Thermally treated $\mathrm{PF}_{14}-b$-Piso ${ }_{n}$ thin films exhibited a clear nanofibrillar structure, and the $d$-spacing was enhanced systematically as the Piso chain length increased. Resistive memory characteristics were explored with a sandwich indium tin oxide/ $\mathrm{PF}_{14}-b-\mathrm{PisO}_{n} \mathrm{~s} / \mathrm{Al}$ device configuration. The enhanced conjugated $\mathrm{PF}$ conducting channels led to stable resistance switching behavior, exhibiting volatile SRAM (static random access memory) $\left(\mathrm{PF}_{14}-b\right.$-Piso $\left.{ }_{10}\right)$ and nonvolatile WORM (write-once-read-many-times) $\left(\mathrm{PF}_{14}-b\right.$ - $\mathrm{PisO}_{20}, \mathrm{PF}_{14}-b$-Piso $60, \mathrm{PF}_{14}-b$ - $\left.\mathrm{Pis0}_{100}\right)$ characteristics with a large ON/OFF ratio $\left(10^{6}\right)$ and a stable retention time $\left(10^{4} \mathrm{~s}\right)$. A more appealing feature is that such memory cells were integrated on a soft poly(dimethylsiloxane) substrate, allowing for the development of a stretchable data storage device. Reliable and reproducible electrical characteristics, including SRAM- and WORM-type memories, could be explored as the device was stretched under an applied tensile strain ranging from 0 to $50 \%$. The studied donor-acceptor copolymers indeed showed great potential for stretchable electronic applications with controllable digital information storage characteristics.

NPG Asia Materials (2016) 8, e298; doi:10.1038/am.2016.112; published online 26 August 2016

\section{INTRODUCTION}

Polymer-based electrical bistable memory devices have been extensively studied owing to their advantages of structural flexibility, low-cost, printability and three-dimensional stacking. ${ }^{1-3}$ Such memories can be switched between high and low resistance states (that is, OFF and ON states) by applying an external electric field. ${ }^{4-12}$ Electrical memory characteristics can generally be divided into two categories, namely nonvolatile (for example, WORM (writeonce-read-many-times) and flash) and volatile memory (for example, dynamic random access memory and SRAM (static random access memory)), which show different tendencies for the stored charges to dispel. The volatility of these digital information storage devices can be controlled by (1) the charge transfer or charge trapping ability of the active materials and (2) the morphological packing structures in the memory layers. Conjugated block copolymers can effectively manipulate charge storage volatility because of their unique self-organization properties, on the basis of the chemical structures of different block segments. ${ }^{3}$ Conjugated rod-coil copolymers have attracted extensive research interest for electronic applications because the conjugated rods typically possess strong interchain $\pi-\pi$ interactions to facilitate conducting channels, whereas the soft coil blocks provide the degree of freedom for polymer chain movement to induce self-assembled molecular packing. ${ }^{6}$

Polyfluorene (PF) is a well-known conjugated moiety for optoelectronics (for example, light-emitting diodes, ${ }^{13}$ field-effect transistors, ${ }^{14}$ and memory devices ${ }^{15-17}$ ) owing to its good electrondonating ability, efficient hole carrier transport and outstanding thermal stability. PF-based rod-coil block copolymers have been explored for resistive memory applications. A volatile SRAM PF- $b$-Poly(2-vinylpyridine) memory with tunable charge storage duration was previously reported. Moreover, an electronwithdrawing [6,6]-phenyl- $\mathrm{C}_{61}$-butyric acid methyl ester was added to associate the donor-acceptor (D-A) charge transfer interaction, converting the memory from volatile SRAM to nonvolatile WORM

${ }^{1}$ Department of Chemical Engineering, National Taiwan University, Taipei, Taiwan; ${ }^{2}$ Graduate School of Chemical Sciences and Engineering, Hokkaido University, Sapporo, Japan; ${ }^{3}$ Institute of Polymer Science and Engineering, National Taiwan University, Taipei, Taiwan and ${ }^{4}$ Faculty of Engineering, Hokkaido University, Sapporo, Japan

Correspondence: Professor T Satoh, Faculty of Engineering, Hokkaido University, Sapporo 060-8628, Japan.

E-mail: satoh@poly-bm.eng.hokudai.ac.jp

or Professor W-C Chen, Department of Chemical Engineering, National Taiwan University, No.1, Section 4, Roosevelt Road, Taipei 10617, Taiwan.

E-mail: chenwc@ntu.edu.tw

Received 13 April 2016; revised 26 May 2016; accepted 14 June 2016 
behavior. ${ }^{16}$ Such a D-A effect, however, must be generated using a polymer composite (that is, adding an extra functional molecule), which may face the bottlenecks of thin-film uniformity and device reproducibility. The development of conjugated rod-coil block copolymers with both donor and acceptor segments that would allow for control over the charge transfer interaction, charge carrier transport and thin-film morphology at the same time would provide significant advantages.

Organic stretchable electronics, on the other hand, have developed rapidly in recent years and possess the potential to be biocompatible with wearable devices, electronic skins and health-care monitors. ${ }^{18-22}$ In the field of resistive memories, flexible and twistable devices have already been reported to exhibit stable memory functionality under deformation, ${ }^{4,17,23,24}$ but research on stretchable devices is still relatively rare, limited by the ductility of active materials. Chen and his coworkers evaluated a stretchable memory device using a poly(3-butylthiophene)/poly(methyl methacrylate) blending film on a pre-strained poly(dimethylsiloxane) (PDMS) substrate. Reliable resistive switching behavior and strong data retention ability were obtained as the devices were stretched by up to $50 \% .^{22}$ Note that the uniformity of the active layer of such stretchable devices may also be limited because two types of polymers are required and could reduce the yield of memory cells in a device. However, stretchable memory devices using donor-acceptor copolymer systems have not yet been developed to the best of our knowledge. The fabrication of a stretchable memory with a single active layer component with good thin-film ductility and tunable electrical properties, therefore, is essential for developing future high-performance data storage electronics.

In this study, we developed a series of rod-coil diblock copolymers, $\mathrm{PF}_{14}-b$-Piso $\mathrm{n}$ s, containing poly[2,7-(9,9-dihexylfluorene)] (PF) electron-donating rods with electron-withdrawing poly(pendent isoindigo) (Piso) coils. The PF and Piso blocks were synthesized through chain-growth Suzuki-Miyaura coupling polymerization ${ }^{25,26}$ and atom transfer radical polymerization methods, ${ }^{27,28}$ respectively, and the target diblock copolymers were obtained via a click coupling reaction (Scheme 1). The thermal, optical and electrochemical characteristics of the studied block copolymers were explored systematically. In addition, the morphology of the prepared $\mathrm{PF}_{14}-b$-Piso $\mathrm{n}_{\mathrm{n}} \mathrm{s}$ thin films was investigated using atomic force microscopy (AFM) and grazing-incidence small-angle X-ray scattering (GISAXS). The resistive switching behaviors were probed, and the charge carrier storage volatility was correlated with the PF/Piso block ratio and the self-assembled nanostructures. One appealing feature is that stretchable memory devices were fabricated by integrating the studied block copolymers on a soft PDMS substrate with a high ON/OFF ratio of $10^{5}$ under $0-50 \%$ applied tensile strain. The studied block copolymers indeed allow for the combination of conjugated rods for superior electrical properties and soft coils for enhanced material ductility, leading to a polymer active layer that possesses good digital information storage characteristics and thin-film stretchability for wearable electronic applications.

\section{MATERIALS AND METHODS}

\section{Fabrication of stretchable memory devices}

A PDMS (Sylgard 184, Dow Corning, Midland, MI, USA) substrate ( $2 \mathrm{~mm}$ thick) was prepared at a ratio of 20:1 (base:crosslinker, w/w) and cured for $12 \mathrm{~h}$ at $120^{\circ} \mathrm{C}$, and was used to transfer a carbon nanotube (CNT) bottom electrode. $\mathrm{CNTs}$ was first spray-coated onto an octadecyltrimethoxysilane-modified $\mathrm{Si}$ wafer, and electrode lines were aligned by a shadow mask. Subsequently, the CNT electrodes were transferred onto a PDMS substrate $(2 \mathrm{~cm} \times 4 \mathrm{~cm})$ and clamped on a glass side. The CNT/PDMS substrate was then stretched to $50 \%$ strain. Next, thermally annealed $\left(100^{\circ} \mathrm{C}\right.$ under a nitrogen atmosphere for $2 \mathrm{~h}$ ) $\mathrm{PF}_{14}-b$-Piso $\mathrm{n}$ thin films (using the same procedure used to produce memory devices on indium tin oxide (ITO) substrates (Supplementary Information) but prepared on an octadecyltrimethoxysilane-modified $\mathrm{Si}$ wafer) were directly transferred onto the pre-strained CNT/PDMS substrate. Finally, Al top electrodes ( $40 \mathrm{~nm}$ thick; perpendicular to the bottom CNT electrode) were deposited using a thermal evaporator at a pressure of $10^{-6}$ torr at a deposition rate of $1 \AA \mathrm{s}^{-1}$ and aligned by a regular shadow mask. The prepared stretchable memory devices were released back to the non-stretching condition (that is, $0 \%$ strain) before testing.
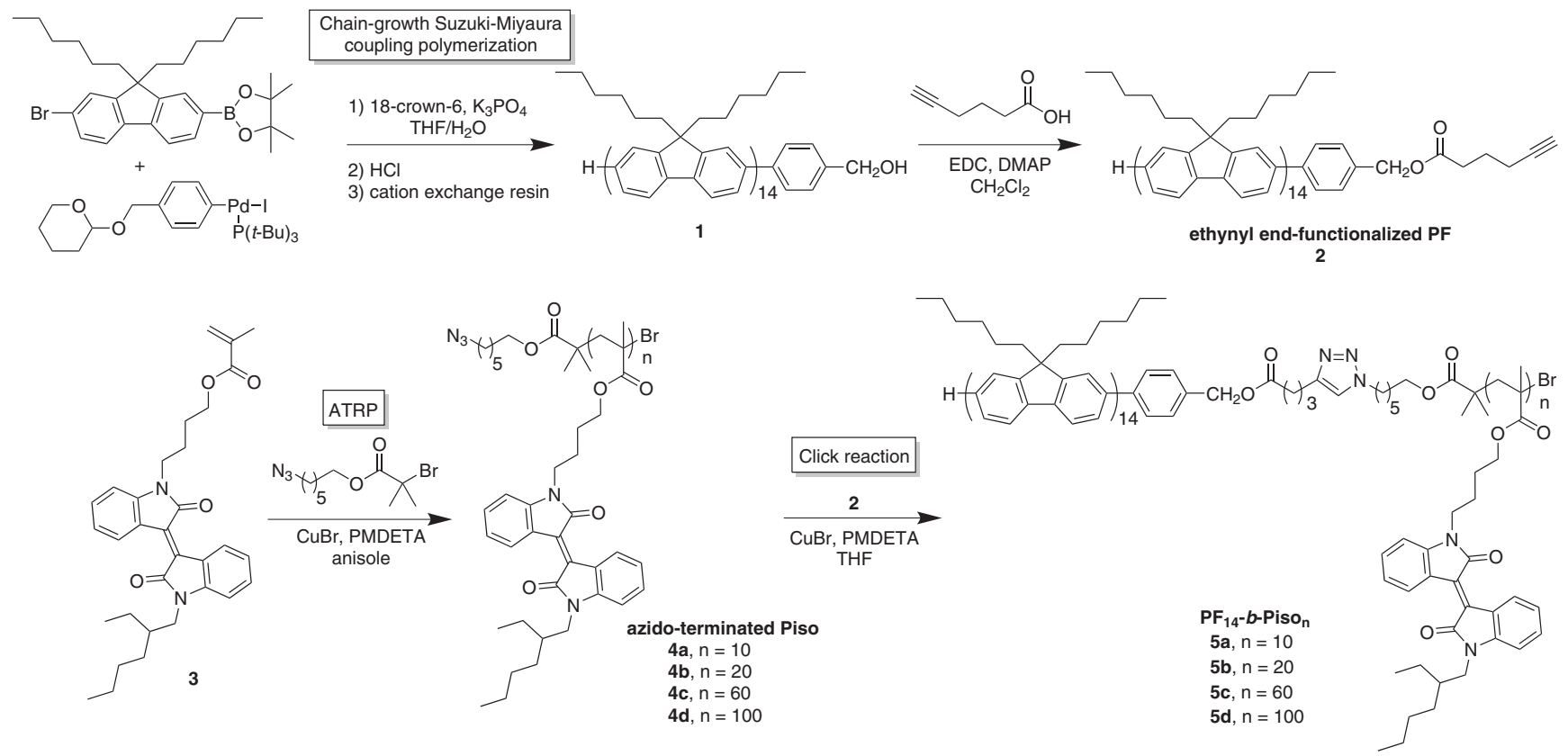

Scheme 1 Synthetic route of $\mathrm{PF}_{14}-b$-Pison rod-coil diblock copolymers. 


\section{RESULTS AND DISCUSSION}

The synthetic route for producing the target rod-coil diblock copolymers, poly[2,7-(9,9-dihexylfluorene)]-block-poly(pendent isoindigo $)\left(\mathrm{PF}_{14}-b\right.$-Piso $\left.\mathrm{n}_{\mathrm{n}}\right)$ is illustrated in Scheme 1. The detailed synthetic parameters are summarized in Table 1 and the Supplementary Information. In accordance with our previous report, ${ }^{29}$ the ethynyl end-functionalized $\mathrm{PF}\left(2, \mathrm{PF}_{14}\right)$ was prepared with an estimated molecular weight $\left(M_{\mathrm{n}(\mathrm{NMR})}\right)$ of $4900 \mathrm{~g} \mathrm{~mol}^{-1}$ (that is, 14 fluorene repeating units). The azido-terminated Piso (4a-d, $\mathrm{N}_{3}$-Piso $\mathrm{n}(n=10,20,60$ and 100, respectively)) coils, on the other hand, were synthesized with various lengths. ${ }^{30}$ The rod-coil diblock copolymers, $\mathrm{PF}_{14}-b-\mathrm{PisO}_{\mathrm{n}} \mathrm{s}(\mathbf{5 a}-\mathbf{d})$, were synthesized through the $\mathrm{Cu}$-catalyzed azido-alkyne click reaction of $\mathrm{PF}_{14}$ and $\mathrm{N}_{3}-\mathrm{Piso}_{\mathrm{n}} \mathrm{s}$, and Fourier transform infrared spectroscopy was employed to determine whether the reaction was completed (Supplementary Figure S2). Four polymers with different coil lengths were successfully produced, and their polymer properties are listed in Table 1. Figure la shows the ${ }^{1} \mathrm{H}-\mathrm{NMR}$ (nuclear magnetic resonance) spectrum of $\mathrm{PF}_{14}-b$-Piso 20 ; proton signals originating from the Piso coils (peaks $a, c, d, e, h, i$ and $j$ ) and PF moiety (peaks $b$ and $l$ ) are clearly observed. A signal attributable to the methylene adjacent to the triazole ring $\left(-\mathrm{N}=\mathrm{N}-\mathrm{N}-\mathrm{CH}_{2}-\right)$, moreover, was observed at 4.24 p.p.m., suggesting that a link between the PF and Piso blocks was formed. The ${ }^{1} \mathrm{H}-\mathrm{NMR}$ signals for the other studied block copolymers were also fitted to our proposed chemical structures (Supplementary Figure S2a). In addition, the results of elemental analyses, including analyses of carbon, hydrogen and nitrogen content, of the $\mathrm{PF}_{14}-b$-Piso $\mathrm{n}$ s are in good agreement with the theoretical content.

The $\mathrm{PF}_{14}-b$ - $\mathrm{Piso}_{20}$ Fourier transform infrared spectroscopy spectrum shows that the characteristic absorption of the azido group at $2098 \mathrm{~cm}^{-1}$ completely disappeared (Figure 1b) because the $\mathrm{N}_{3}$-Piso 20 and the ethynyl end-functional PF were fully reacted in the click reaction system.

The size exclusion chromatography (SEC) traces of $\mathrm{N}_{3}-\mathrm{Piso}_{\mathrm{n}} \mathrm{S}$ and $\mathrm{PF}_{14}-b-\mathrm{PisO}_{\mathrm{n}} \mathrm{s}$ are depicted in Figure $1 \mathrm{c}$ and Supplementary Figure S2c. The elution peak of $\mathrm{PF}_{14}-b$ - $\mathrm{PisO}_{n} \mathrm{~S}$ shifted to the higher molecular weight region after the click reaction compared with that of $\mathrm{N}_{3}-\mathrm{PisO}_{n}$, leading to a number-averaged molecular weights $\left(M_{\mathrm{n}(\mathrm{SEC})}\right)$ in the range of 9500-58 $600 \mathrm{~g} \mathrm{~mol}^{-1}$ depending on the controllable Piso length. The results of ${ }^{1} \mathrm{H}-\mathrm{NMR}$, Fourier transform infrared spectroscopy, SEC and elemental analysis suggest that well-defined $\mathrm{PF}_{14}-b$ - Piso $_{n}$ s with Piso coil lengths of 10, 20, 60 and 100 repeating units were effectively produced through the click reaction between $\mathrm{PF}_{14}$ and $\mathrm{N}_{3}$ - $\mathrm{Piso}_{\mathrm{n}} \mathrm{s}$. All the studied block copolymers are well soluble in common organic solvents, such as chloroform, tetrahydrofuran and toluene.
Thermogravimetric analysis and differential scanning calorimetry were used to detect the thermal properties of $\mathrm{PF}_{14}, \mathrm{~N}_{3}$ - $\mathrm{Piso}_{100}$ and $\mathrm{PF}_{14}-b-\mathrm{Piso}_{\mathrm{n}}$, as illustrated in Supplementary Figure S3 and

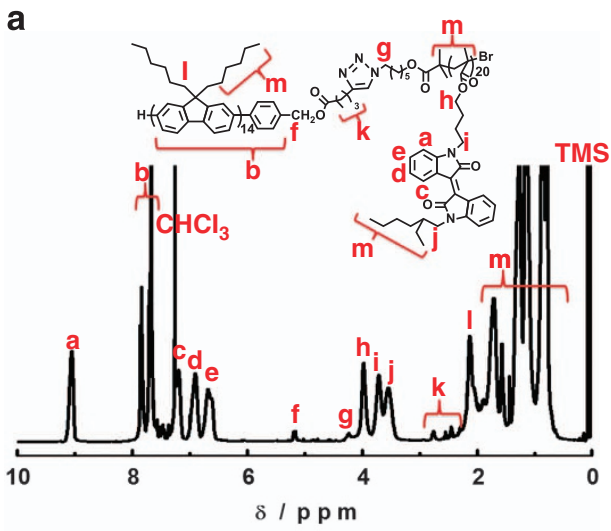

b $\mathrm{N}_{3}$-Piso 20

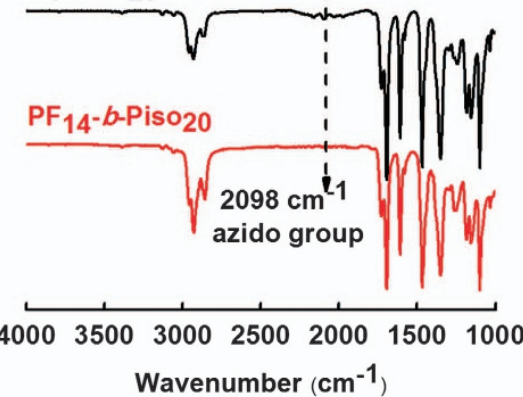

C

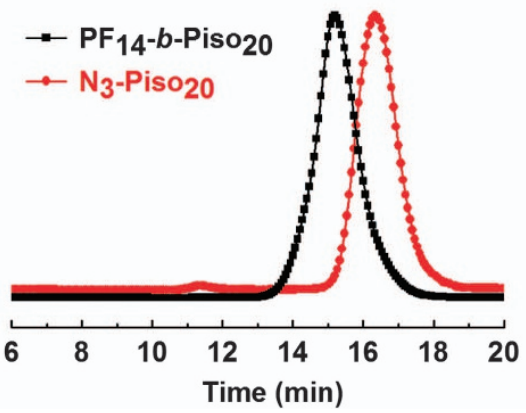

Figure 1 (a) ${ }^{1} \mathrm{H}$-NMR spectra of $\mathrm{PF}_{14}$-b-Piso 20 in $\mathrm{CDCl}_{3}$. (b) FTIR spectra and (c) SEC profiles in tetrahydrofuran (THF) eluent of $\mathrm{N}_{3}-\mathrm{PisO}_{20}$ and $\mathrm{PF}_{14}$ $b$-Piso 20. FTIR, Fourier transform infrared spectroscopy; NMR, nuclear magnetic resonance; PF, poly[2,7-(9,9-dihexylfluorene)]; Piso, poly(pendent isoindigo); SEC, size exclusion chromatography; TMS, tetramethylsilane.

Table 1 Synthesis and physical properties of $\mathrm{PF}_{14}, \mathrm{~N}_{3}-\mathrm{Piso}_{100}$ and $\mathrm{PF}_{14}-b-\mathrm{Piso}_{n}$ block copolymers

\begin{tabular}{|c|c|c|c|c|c|c|}
\hline Sample & $\mathrm{M}_{n(\mathrm{NMR})^{\mathrm{a}}}\left(\mathrm{g} \mathrm{mol}^{-1}\right)$ & $\mathrm{M}_{n(S E C)^{\mathrm{b}}}\left(\mathrm{g} \mathrm{mol}^{-1}\right)$ & $\mathrm{M}_{w} \mathrm{M}_{n}^{\mathrm{b}}$ & $\mathrm{T}_{d}\left({ }^{\circ} \mathrm{C}\right)$ & $\mathrm{T}_{g}\left({ }^{\circ} \mathrm{C}\right)$ & $\mathrm{d}$-Spacing ${ }^{\mathrm{c}}\left(n m^{-1}\right)$ \\
\hline $\mathrm{PF}_{14}$ & 4900 & 7800 & 1.33 & 399 & 69.3 & NA \\
\hline $\mathrm{PF}_{14}-b$-Piso 10 & 9500 & 28000 & 1.31 & 332 & 73.7 & 16.8 \\
\hline $\mathrm{PF}_{14}-b-\mathrm{PisO}_{20}$ & 14800 & 29500 & 1.26 & 320 & 78.3 & 20.8 \\
\hline $\mathrm{PF}_{14}-b$-Piso 60 & 34700 & 32500 & 1.25 & 316 & 81.9 & 24.4 \\
\hline $\mathrm{PF}_{14}-b$-Piso 100 & 58600 & 35500 & 1.22 & 308 & 83.8 & 29.2 \\
\hline $\mathrm{N}_{3}$-Piso 100 & 57200 & 33200 & 1.22 & 277 & 87.1 & NA \\
\hline
\end{tabular}

Abbreviations: GISAXS, grazing-incidence small-angle X-ray scattering; NA, not applicable; NMR, nuclear magnetic resonance; PF, poly[2,7-(9,9-dihexylfluorene)]; Piso, poly(pendent isoindigo); SEC, size exclusion chromatography.

aEstimated by ${ }^{1} \mathrm{H}-\mathrm{NMR}$ in $\mathrm{CDCl}_{3}$.

betermined from SEC using PSt standards in THF.

cDetermined by GISAXS measurement using thermally annealed thin films. 
summarized in Table 1. The thermal decomposition temperatures ( $T_{\mathrm{d}}, 5 \%$ weight-loss) of $\mathrm{PF}_{14}$ and $\mathrm{N}_{3}-\mathrm{Piso}_{100}$ are 400 and $277^{\circ} \mathrm{C}$, respectively. The $T_{\mathrm{d}}$ values of the $\mathrm{PF}_{14}-b-\mathrm{PisO}_{\mathrm{n}} \mathrm{s}$ are located between those associated with the decomposition of the PF and Piso segments. Although the thermal degradation of these block copolymers could occur at two distinct $T_{\mathrm{d}}$ temperatures, the narrow temperature ranges of the two blocks make them indistinguishable. On the basis of differential scanning calorimetry heating traces, on the other hand, the studied $\mathrm{PF}_{14}-b$ - Piso $_{\mathrm{n}} \mathrm{s}$ exhibit a broad transition temperature, with the glass transition temperatures $\left(T_{\mathrm{g}}\right)$ ranging from 73.7 to $83.8^{\circ} \mathrm{C}$, which are between the $T_{\mathrm{g}}$ of the parent $\mathrm{PF}\left(69.3^{\circ} \mathrm{C}\right)$ and Piso $\left(87.1^{\circ} \mathrm{C}\right)$ blocks. Similarly, we observed only one broad thermal transition on the prepared block copolymers instead of two distinct $T_{\mathrm{g}}$ values, which was also caused by the similar $T_{\mathrm{g}}$ values of $\mathrm{PF}\left(69.3^{\circ} \mathrm{C}\right)$ and Piso $\left(87.1^{\circ} \mathrm{C}\right)$. Thus, the observation of only one transition temperature in the studied block copolymers does not mean that there is no microphase separation.

Ultraviolet-visible absorption spectra of the synthesized polymer films of $\mathrm{PF}_{14}, \mathrm{Piso}_{100}$ and $\mathrm{PF}_{14}-b$ - $\mathrm{Piso}_{\mathrm{n}} \mathrm{s}$ are shown in Figure $2 \mathrm{a}$. Their corresponding maximum absorption wavelengths $\left(\lambda_{\max }\right)$ and optical

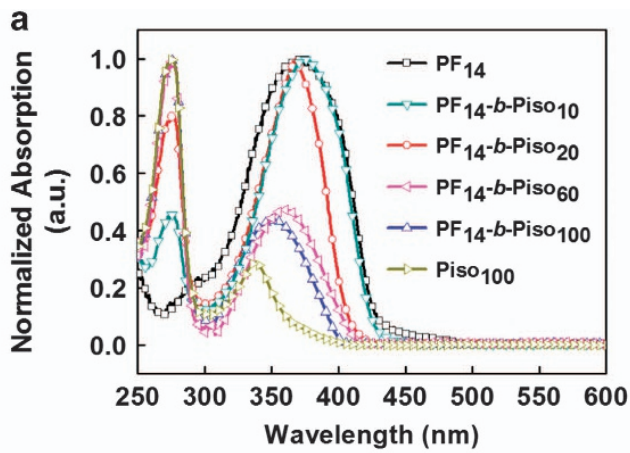

b

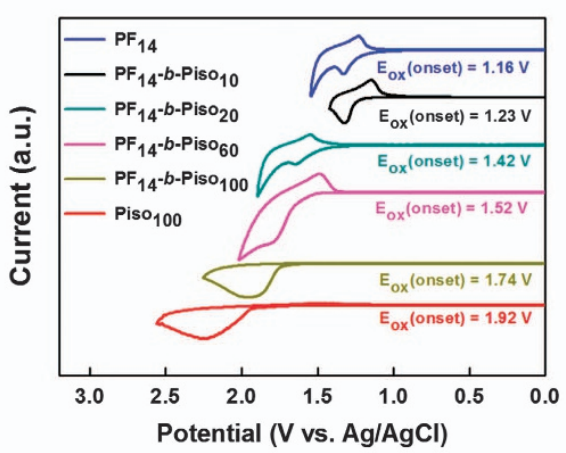

C

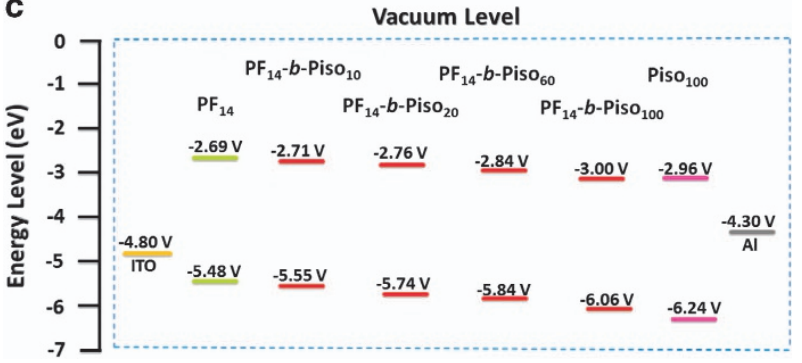

Figure 2 (a) UV-vis absorption spectra, (b) cyclic voltammetry curves and (c) energy levels of the studied materials. ITO, indium tin oxide; PF, poly [2,7-(9,9-dihexylfluorene)]; Piso, poly(pendent isoindigo); UV-vis, ultravioletvisible. band gaps $\left(E \mathrm{~g}^{\mathrm{opt}}\right)$, in addition, are summarized in Table $2 . \mathrm{PF}_{14}$ clearly exhibits a $\lambda_{\max }$ at $371 \mathrm{~nm}$, whereas the Piso homopolymer (that is, Piso $_{100}$ ) shows two spin allowed $\pi-\pi^{\star}$ transitions at 276 and $337 \mathrm{~nm}$. All the $\mathrm{PF}_{14}-b$-Piso ${ }_{\mathrm{n}}$-based thin films possessed two distinct signals: (1) a narrow peak at $\sim 276 \mathrm{~nm}$, attributed to the absorption of Piso coils, the intensity of which increased with the content of Piso; (2) a broad absorption peak over the range of 350-373 nm, which was affected by both the PF and Piso moieties, and the intensity of which decreased distinctively with the blue shift in $\lambda_{\max }$ from 373 to $350 \mathrm{~nm}$ as the content of the Piso segment increased. The optical band gaps $\left(E \mathrm{~g}^{\mathrm{opt}}\right)$ of $\mathrm{PF}_{14}$ and $\mathrm{Piso}_{100}$ estimated from the onset of solid-state absorption are 2.79 and $3.28 \mathrm{eV}$, respectively. Indeed, the series of rod-coil copolymers, $\mathrm{PF}_{14}-b$ - $\mathrm{PisO}_{\mathrm{n}} \mathrm{s}$, showed $\mathrm{Eg}^{\mathrm{opt}}$ values between those of their parent building blocks (that is, $\mathrm{PF}$ and Piso) of $2.84\left(\mathrm{PF}_{14}-b\right.$ - $\left.\mathrm{Piso}_{10}\right)$, $2.98\left(\mathrm{PF}_{14}-b\right.$ - $\left.\mathrm{PisO}_{20}\right), 3.00\left(\mathrm{PF}_{14}-b-\mathrm{PisO}_{60}\right)$ and $3.06\left(\mathrm{PF}_{14}-b\right.$ - $\left.\mathrm{PisO}_{100}\right)$ $\mathrm{eV}$. It should be noted that the Eg $\mathrm{g}^{\text {opt }}$ values of the studied block copolymers became slightly larger owing to the increased Piso content, indicating that the PF/Piso coil-to-rod ratio can significantly affect their optoelectronic properties.

Furthermore, the solid-state photoluminescence (PL) spectra (Supplementary Figure S4) were characterized to clarify the strength of the intermolecular interaction between the electron-donating PF (donor) and electron-withdrawing Piso (acceptor) in the studied block copolymer. $\mathrm{PF}_{14}$ exhibited the strongest photoluminescence emission, and possessed two distinct peaks located at 420 and $445 \mathrm{~nm}$, which are commonly observed among conjugated poly(fluorene)s. As the content of the Piso acceptor was increased, the photoluminescence emission was remarkably quenched owing to the donor-acceptor interaction, indicating charge transfer in the $\mathrm{PF}_{14}-b$ - $\mathrm{Piso}_{\mathrm{n}}$ thin films. ${ }^{31}$

The electrochemical properties of the studied block copolymers were investigated by cyclic voltammetry to understand the relationship between chemical structures and energy levels, as depicted in Figure 2b and summarized in Table 2. The highest occupied molecular orbital (HOMO) energy levels were calculated from the onset of oxidation waves in the cyclic voltammetry curves with reference to ferrocene $(4.8 \mathrm{eV})$, whereas the lowest unoccupied molecular orbital (LUMO) energy levels were estimated from the difference between the optical band gap and HOMO level. The HOMO levels obtained for $\mathrm{PF}_{14}$, $\mathrm{PF}_{14}-b$-Piso $10, \mathrm{PF}_{14}-b$-Piso $20, \mathrm{PF}_{14}-b$ - $\mathrm{Piso}_{60}, \mathrm{PF}_{14}-b$ - $\mathrm{Piso}_{100}$ and $\mathrm{Piso}_{100}$ were $-5.48,-5.55,-5.74,-5.84,-6.06$ and $-6.24 \mathrm{eV}$, respectively, and their corresponding LUMO levels were $-2.69,-2.71,-2.76$, $-2.84,-3.00$ and $-2.96 \mathrm{eV}$, respectively. Both the HOMO and LUMO energy levels of $\mathrm{PF}_{14}$ - $b$-Piso $\mathrm{P}_{\mathrm{n}}$ were systematically reduced with increasing Piso length, as illustrated in Figure 2c. The HOMO energy

Table 2 Optical and electrochemical properties of the studied materials

\begin{tabular}{|c|c|c|c|c|}
\hline Sample & $\lambda_{\max }{ }^{\text {filma }}(n m)$ & $\mathrm{Eg} g^{\mathrm{optb}}(\mathrm{eV})$ & HOMO (eV) & $\angle U M O^{C}(\mathrm{eV})$ \\
\hline $\mathrm{PF}_{14}$ & 371 & 2.79 & -5.48 & -2.69 \\
\hline $\mathrm{PF}_{14}-b$-Piso 10 & 275,373 & 2.84 & -5.55 & -2.71 \\
\hline $\mathrm{PF}_{14}-b$-Piso 20 & 277,367 & 2.98 & -5.74 & -2.76 \\
\hline $\mathrm{PF}_{14}-b$-Piso 60 & 276,360 & 3.00 & -5.84 & -2.84 \\
\hline $\mathrm{PF}_{14}-b$-Piso 100 & 277,350 & 3.06 & -6.06 & -3.00 \\
\hline $\mathrm{N}_{3}$-Piso 100 & 276,337 & 3.28 & -6.24 & -2.96 \\
\hline
\end{tabular}

Abbreviations: HOMO, highest occupied molecular orbital; PF, poly[2,7-(9,9-dihexylfluorene)]; Piso, poly(pendent isoindigo); LUMO, lowest unoccupied molecular orbital; UV-vis, ultravioletvisible; .

aSpin-coated film from chloroform solution onto a quartz substrate.

${ }^{b}$ Estimated from onset wavelength of the UV-vis absorption.

${ }^{c}$ The LUMO energy level was calculated by the equation LUMO $(\mathrm{eV})=\mathrm{HOMO}+E_{\mathrm{g}}{ }^{\text {opt }}$. 
level of $\mathrm{PF}_{14}$ - $b$-Pison was affected by both the electron-donating $\mathrm{PF}$ and electron-withdrawing Piso blocks. The intrachain or interchain charge transfer of $\mathrm{PF}$ and Piso in the block copolymers led to a decrease in the HOMO energy level with increasing Piso chain length. It should be noted that the microphase separation of the two blocks could prevent intrachain charge transfer, and thus interchain charge transfer would be significant in the case of thin films, leading to a change in the HOMO level with increasing Piso block length.

Nanostructures on $\mathrm{PF}_{14}-b$ - $\mathrm{PisO}_{\mathrm{n}}$ thin-film surfaces were investigated using AFM. For the as-cast polymer films (that is, without thermal annealing treatment), no distinct surface structure was observed for any of the studied block copolymers (Supplementary Figure S5). The thermally treated $\mathrm{PF}_{14}-b$-Piso $\mathrm{n}_{\mathrm{n}}$ thin films, however, presented a distinct nanofibrillar structure on the surface (Figure 3). Short and rod-like aggregates were observed on the surface of $\mathrm{PF}_{14}$ - $b$ - $\mathrm{Piso}_{10}$ films (Figure $3 \mathrm{a}$ ) owing to the strong $\pi-\pi$ interaction of the PF-conjugated segments. As the content of Piso coils was increased, more interestingly, a fibrillar structure was clearly observed (Figure $3 \mathrm{~b}-\mathrm{d}$ ). This structure is attributed to the molecular packing of conjugated PF domains, and the size and density of these nanofibers could be controlled by tuning the PF/Piso block ratio. The driving force for
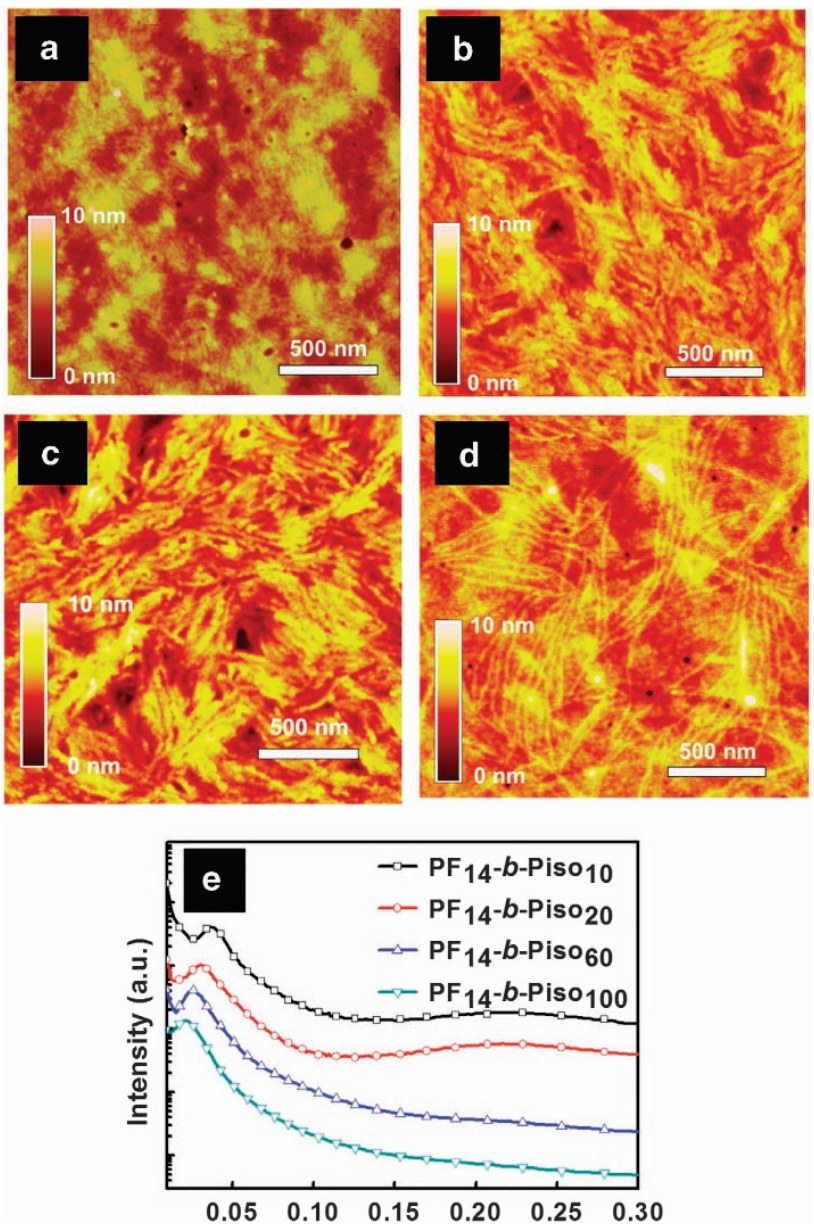

Figure 3 AFM topographies of (a) $\mathrm{PF}_{14}$-b-Piso 10 , (b) $\mathrm{PF}_{14}$-b-Piso 20 , (c) $\mathrm{PF}_{14}$ $b$ - Piso $_{60}$ and (d) $\mathrm{PF}_{14}-b$-Piso 100 thin films. (e) One-dimensional GISAXS profile $\left(q_{y}\right.$ scan at $q_{z}=0.027 \AA^{-1}$ ) of $\mathrm{PF}_{14}-b$-Piso ${ }_{\mathrm{n}}$ thin films. All of the block copolymer thin films were annealed at $100^{\circ} \mathrm{C}$ for $2 \mathrm{~h}$. AFM, atomic force microscopy; GISAXS, grazing-incidence small-angle X-ray scattering; $\mathrm{PF}$, poly[2,7-(9,9-dihexylfluorene)]; Piso, poly(pendent isoindigo). creating these self-assembly morphologies on our block copolymer surfaces is the $\pi$-electron interaction between the conjugated PF rods and the nonconjugated soft chains (Piso). The nanofibrillar $\mathrm{PF}$-aggregated domains, hence, can be formed owing to a balance between the thermodynamics and kinetics of crystalline/amorphous (that is, PF/Piso) domains.

To further investigate the self-assembly behaviors of the $\mathrm{PF}_{14}-b$-Piso $\mathrm{n}_{\mathrm{n}} \mathrm{s}$, we examined the thermally annealed $\mathrm{PF}_{14}-b$ - $\mathrm{Piso}_{\mathrm{n}}$ thin films using GISAXS. Figure $3 e$ shows the one-dimensional GISAXS profiles of thermally annealed thin films of the studied block copolymers. Thin films prepared from $\mathrm{PF}_{14}-b$ - $\mathrm{Piso}_{10}, \mathrm{PF}_{14}-b$ - $\mathrm{Piso}_{20}$, $\mathrm{PF}_{14}-b$-Piso 60 and $\mathrm{PF}_{14}-b$-Piso ${ }_{100}$ exhibited a clear first-order scattering peak located at $q^{*}=0.0374,0.0302,0.0257$ and $0.0215 \AA^{-1}$, respectively, and the corresponding $d$-spacing values (that is, average center-to-center distance of the $\mathrm{PF}$ nanostructures), calculated from the scattering formula $d=2 \pi / q^{*}$, were $16.8,20.8$, 24.4 and $29.2 \mathrm{~nm}$, respectively. The GISAXS results reveal that the

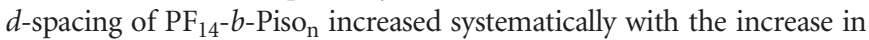
the Piso chain length from 10 to 100 repeating units, which is consistent with the recorded AFM phase images. The abovementioned morphological results demonstrate that the thin films on the basis of the studied $\mathrm{PF}_{14}-b$-Piso $\mathrm{n}_{\mathrm{n}}$ block copolymers possess well-defined self-assembled nanostructures after thermal annealing, and these tunable nanofibrillar structures may further influence the electrical characteristics effectively.

Figure 4 and Supplementary Figure S6 show the representative current density-voltage $(J-V)$ characteristics of devices fabricated from $\mathrm{PF}_{14}, \mathrm{Piso}_{100}$ and $\mathrm{PF}_{14}-b$ - $\mathrm{Piso}_{n} \mathrm{~s}$. The structure-property relationship was probed using a cross bar array-designed two-terminal resistive memory with a device configuration of ITO/ $\mathrm{PF}_{14}-b-\mathrm{Piso}_{\mathrm{n}} / \mathrm{Al}$. A voltage was applied, with a step of $0.05 \mathrm{~V}$, to the top electrode (Al). Stable electrical switching behavior could be obtained using thermally annealed $\mathrm{PF}_{14}-b$-Pison $\mathrm{n}_{\mathrm{n}}$ thin films. The $J-V$ curves of the $\mathrm{PF}_{14}$ - $b$-Piso 10 -based device (Figure $4 \mathrm{a}$ ) were initially in a high resistance state (that is, OFF state; ' 0 ' signal in data storage) with a current density in the range of $10^{-9}-10^{-10} \mathrm{~A}$ as the voltage was swept from 0 to $-1.5 \mathrm{~V}$. Then, the current abruptly switched from a high resistance state to a low resistance state (that is, ON state; ' 1 ' signal in data storage) with a threshold voltage of approximately $-1.5 \mathrm{~V}$. It should be noted that this electronic transition from the OFF state to the $\mathrm{ON}$ state during the scanning serves as the writing process. The $\mathrm{PF}_{14}-b$ - $\mathrm{PisO}_{10}$ memory can be kept in the $\mathrm{ON}$ state using a subsequent sweep from 0 to $-4.0 \mathrm{~V}$ after writing (sweep 2), showing bistable conductance states with an ON/OFF current ratio of up to $10^{4}$. A third sweep was conducted using the same memory cell after turning off the power for $\sim 5 \mathrm{~min}$, and the device could be reprogrammed from the $\mathrm{OFF}$ state to the $\mathrm{ON}$ state once again with a turn-on voltage of $-1.5 \mathrm{~V}$. We therefore investigated the device under repeating writing/relaxation cycles, observing that the device could be maintained in the $\mathrm{ON}$ state for a period of 5-10 min after the removal of the power supply and then gradually switched back to the OFF state, indicating that the $\mathrm{PF}_{14}$ - $b$-Piso ${ }_{10}$-based memory device exhibits volatile SRAM behavior.

The $J-V$ curves of $\mathrm{PF}_{14}-b-\mathrm{PisO}_{20^{-}}, \quad \mathrm{PF}_{14}-b$ - $\mathrm{PisO}_{60}$-and $\mathrm{PF}_{14}$-b-Piso ${ }_{100}$-based memory devices, on the other hand, illustrated similar electrical switching characteristics through five voltage sequences (Figure $4 \mathrm{~b}-\mathrm{d}$ ): 0 to $-4 \mathrm{~V}$ (sweep 1); 0 to $-4 \mathrm{~V}$ (sweeps 2 and 4); and 0 to $4 \mathrm{~V}$ (sweeps 3 and 5). The memory cell was initially in the high-resistance OFF state and then switched to the low-resistance ON state at the appropriate threshold voltage. The current level was then maintained in the $\mathrm{ON}$ state for the subsequent negative or 

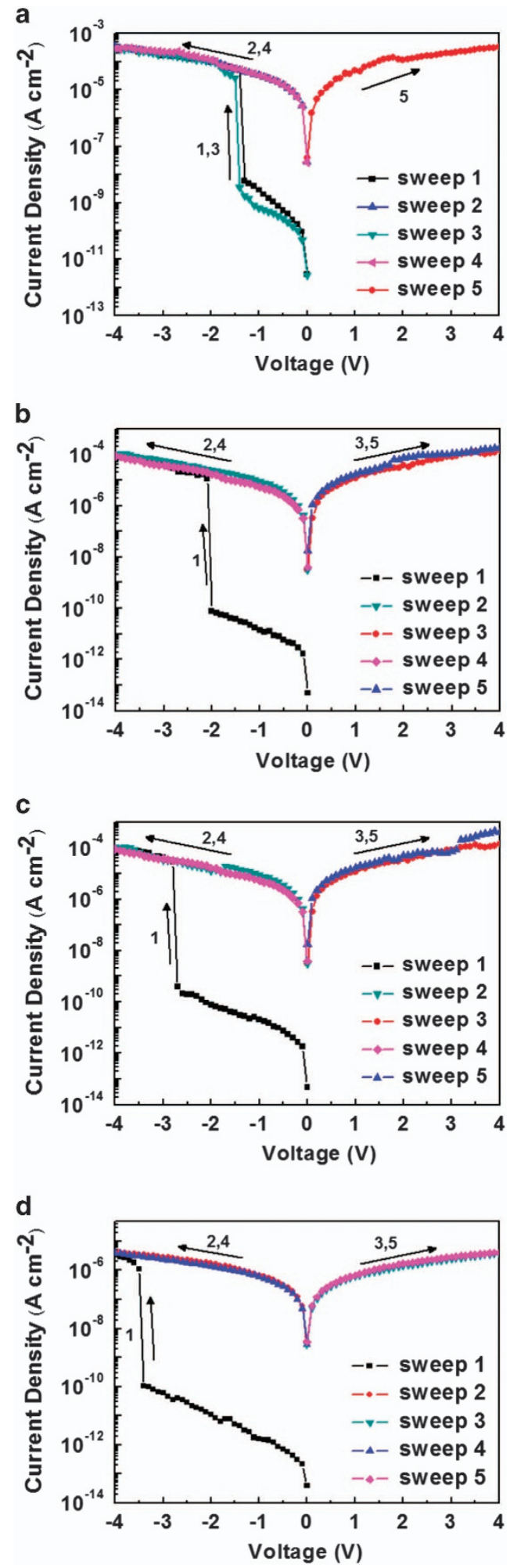

Figure $4 \mathrm{~J}-V$ characteristics of the (a) $\mathrm{PF}_{14}-b$-Piso $10^{-}$, (b) $\mathrm{PF}_{14}-b$ - $\mathrm{PisO}_{20^{-}}$, (c) $\mathrm{PF}_{14}-b$-Piso $60^{-}$and (d) $\mathrm{PF}_{14}-b$-Piso ${ }_{100}$-based memory devices on ITO substrates. The block copolymer active layer was thermally annealed at $100{ }^{\circ} \mathrm{C}$ for $2 \mathrm{~h}$. ITO, indium tin oxide; PF, poly[2,7-(9,9-dihexylfluorene)]; Piso, poly(pendent isoindigo).

positive sweeps (sweeps 2 and 3) with an ON/OFF current ratio of $10^{5}-10^{6}$ at $-1 \mathrm{~V}$. This memory device, moreover, could not return to the OFF state after turning the power off or even applying a reverse bias (sweeps 4 and 5), suggesting nonvolatile WORM memory characteristics.

The abovementioned results suggest that electrical switching properties are strongly dependent on the PF/Piso ratio in the block copolymers. The conjugated $\mathrm{PF}$ rods (that is, $\mathrm{PF}_{14}$ ) possess a relatively high $p$-channel charge carrier mobility and show conductor characteristics without any changes in resistance state (Supplementary Figure S6a). However, only highly resistant insulating behavior was obtained for the pendent electron-withdrawing isoindigo coils (that is, Piso $_{100}$ ) owing to their nonconjugated backbone (Supplementary Figure S6b). Thus, resistive memory switching was induced from the PF conducting channels in an insulating Piso matrix, leading to tunable charge storage volatility by manipulating the PF/Piso block ratio and controlling the surface structure of $\mathrm{PF}_{14}-b$ - $\mathrm{PisO}_{\mathrm{n}} \mathrm{S}$.

The memory characteristics of the $\mathrm{PF}_{14}-b$ - $\mathrm{PisO}_{\mathrm{n}} \mathrm{s}$-based as-cast thin films (that is, without thermal annealing) were also addressed to clarify the effects of the thermal annealing treatment and nanostructured morphologies on the resistive switching behavior (Supplementary Figure S7). The memory characteristics of the studied polymers were generally similar (SRAM $\left(\mathrm{PF}_{14}-b\right.$ - $\left.\mathrm{PisO}_{10}\right)$ or WORM $\left(\mathrm{PF}_{14}-b\right.$ - $\mathrm{PisO}_{20}$ and $\mathrm{PF}_{14}-b$ - $\left.\mathrm{PisO}_{60}\right)$ ) to those of the active thin film with or without thermal annealing. However, the characteristics were different from those of the $\mathrm{PF}_{14}$ - $b$-Piso ${ }_{100}$-based device. The as-cast $\mathrm{PF}_{14}$ - $b$ - $\mathrm{Piso}_{100}$ memory could not generate any resistance conversion under a voltage bias, whereas the corresponding thermally annealed thin film could exhibit WORM-type characteristics, because conducting channels were formed in the PF nanostructures, as indicated by AFM imaging. Statistics associated with the memory parameters, such as the threshold voltage, ON state current level and ON/OFF ratio, are summarized in Figure 5. The operating deviation of the threshold voltage (Figure 5a and Supplementary Figure S8) was significantly reduced as the studied devices were treated by thermal annealing. The threshold voltage, furthermore, increased with the increasing length of the Piso segments, which was mainly attributed to the content of the PF and Piso blocks. As the content of PF was decreased with increasing Piso length, the effective conducting region was minimized and the charge injection barrier (that is, energy difference between the HOMO level and the work function of the ITO electrode) was increased such that the device required a larger electrical driving force to be switched on. The ON state current level and the ON/OFF current ratio of the studied devices were also investigated statistically (Figure 5b). The ON state current density was significantly enhanced after thermal annealing owing to the nanofibrillar structures as well as the effective conducting channels of the conjugated PF segments. Thus, the current level and, in turn, the ON/OFF current ratio of the memory device were increased. In addition, the value of the $\mathrm{ON}$ state current was decreased with the increase in the length of the Piso coils. This trend is also attributed to the relative content of PF and Piso blocks because the charge transport region was diminished as the content of Piso was increased, and thus, a lower ON current response was obtained.

The digital information retention stability of $\mathrm{PF}_{14}-b$-Piso ${ }_{\mathrm{n}}$-based memory devices was also explored (Supplementary Figure S9). The memory cells could maintain either an ON or OFF state for at least $10000 \mathrm{~s}$ under a bias of $-1 \mathrm{~V}$ and exhibited high ON/OFF ratios of $10^{5}-10^{6}$, demonstrating that the studied memories have stable resistive switching characteristics to distinguish each memory (that is, different resistance) state. Furthermore, the cumulative probability of the $\mathrm{ON}$ and OFF state switching current for the studied memory cells is presented in Supplementary Figure S10. Stable and reliable current responses were also observed. The abovementioned results clearly indicate that the thermally annealed $\mathrm{PF}_{14}-b$ - $\mathrm{Piso}_{10}$ thin film exhibited 

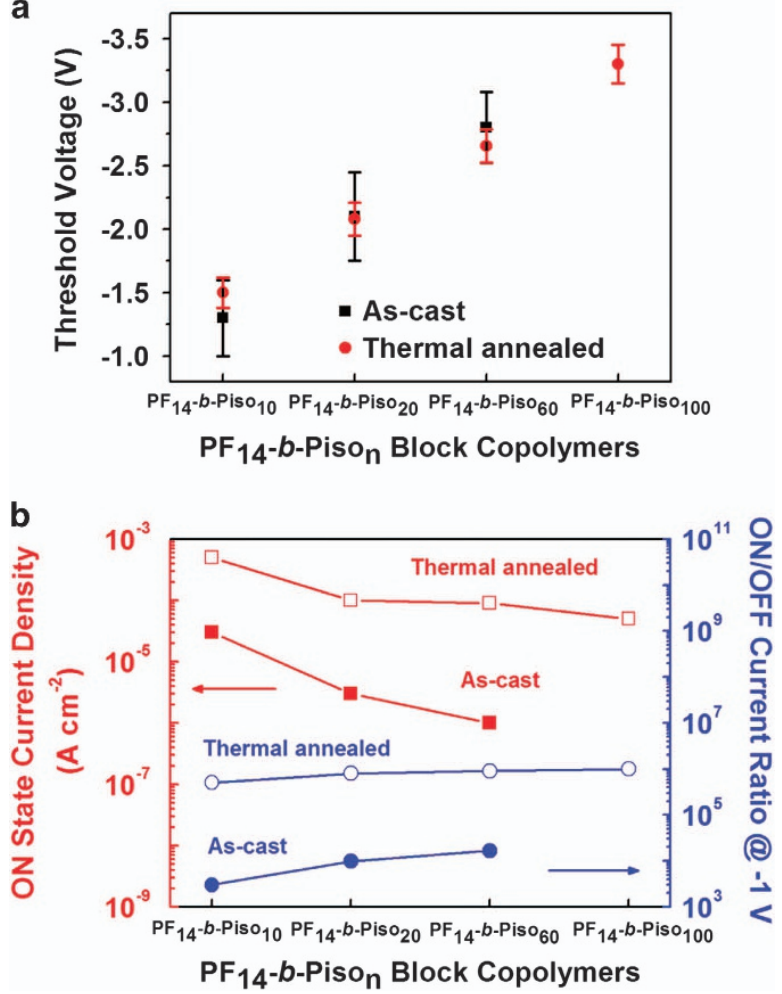

Figure 5 Statistical characteristics, including (a) threshold voltage, and (b) ON state current density and ON/OFF current ratio at $-1 \mathrm{~V}$, of $\mathrm{PF}_{14}-b$-Piso ${ }_{n}$-based memory devices using as-cast and thermally annealed active layer. PF, poly[2,7-(9,9-dihexylfluorene)]; Piso, poly(pendent isoindigo).

volatile SRAM memory behavior, whereas the other studied block copolymers showed nonvolatile WORM characteristics. The thermal annealing process, more importantly, can efficiently improve the stability and reproducibility of the memory cells. The threshold voltage, the $\mathrm{ON}$ state current and the ON/OFF ratio, moreover, can be controlled through the $\mathrm{PF} /$ Piso block ratio. High-performance memory devices with tunable charge storage volatility can thus be achieved through molecular design, and the unique morphological characteristics of block copolymers provide a facile platform for enhancing the resistive switching properties.

The energy level diagrams of the studied block copolymer-based memory devices with low (that is, $\mathrm{PF}_{14}-b$ - $\mathrm{Piso}_{10}$ ) and high (that is, $\mathrm{PF}_{14}$-b-Piso ${ }_{100}$ ) Piso contents are shown in Figure $6 \mathrm{a}$ and $\mathrm{b}$, respectively, to elucidate the conduction mechanism of the resistive switching. On the basis of the studied device configuration of $\mathrm{ITO} / \mathrm{PF}_{14}-b$ - $\mathrm{PisO}_{\mathrm{n}} / \mathrm{Al}$, the energy barrier between the bottom ITO contact and HOMO level of the $\mathrm{PF}_{14}$ donor $(0.68 \mathrm{eV})$ is much smaller than that between the $\mathrm{Al}$ electrode and the LUMO level of the Piso 100 acceptor $(1.34 \mathrm{eV})$, indicating that the device is initially driven by hole carrier injection from ITO to the HOMO level of the active materials. The trapped holes in PF can then attract the opposite charge carriers and electrons, under an applied electric field. Electric field-induced charge transfer between electron donors (that is, $\mathrm{PF}$ ) and acceptors (that is, Piso) may then occur, and electrons can be transferred from the PF rods to the Piso coils by excitation under a sufficiently high applied voltage, especially in an environment characterized by a high Piso content. Such charge transfer interaction leads to a stable charge separation state, and effective conducting channels would be established in the active layer with reduced charge transport a
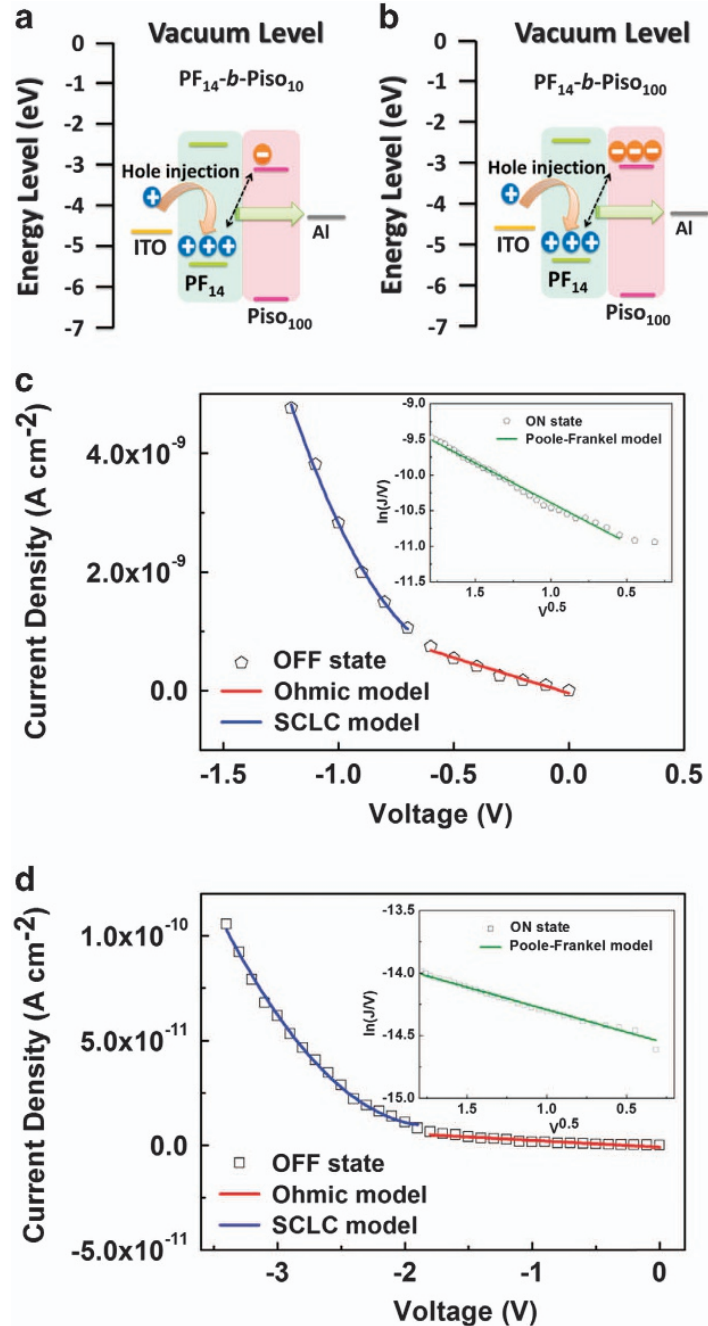

Figure 6 Proposed resistive switching charge transfer effect of the studied memory device with (a) high-PF/Piso $\left(\mathrm{PF}_{14}-b\right.$-Piso 10 ) and (b) low-PF/ Piso ratio $\left(\mathrm{PF}_{14}-b\right.$ - $\left.\mathrm{PisO}_{100}\right)$. Experimental and fitted $J-V$ characteristics of the ON and OFF states for (c) $\mathrm{PF}_{14^{-}} b$ - $\mathrm{PisO}_{10^{-}}$and (d) $\mathrm{PF}_{14^{-}}-b$-Piso $100^{-}$ based memory devices. ITO, indium tin oxide; PF, poly[2,7-(9,9dihexylfluorene)]; Piso, poly(pendent isoindigo); SCLC, space-charge-limitedconduction.

resistance. ${ }^{32}$ The resistive switching characteristics of the studied memories are affected by the donor-acceptor charge transfer, energy barrier and morphology of the studied block copolymers. As the content of Piso coils $\left(\mathrm{PF}_{14}-b\right.$ - $\mathrm{PisO}_{20}, \mathrm{PF}_{14}-b$ - $\mathrm{Piso}_{60}$, and $\mathrm{PF}_{14}-b$-Piso $\left.{ }_{100}\right)$ increases, the polymer active layer exhibits a stronger $\mathrm{D}-\mathrm{A}$ charge transfer interaction to induce more charge carriers and a larger phase separation $d$-spacing to prevent hole-electron recombination, creating the stable $\mathrm{ON}$ state of the memory device. Nonvolatile memory characteristics, thus, were obtained. In contrast, $\mathrm{PF}_{14}-b$ - $\mathrm{PisO}_{10}$-based active layer could not stabilize the induced charges after programming such that the device would return to the OFF state after turning off the power. The energy barrier between ITO and $\mathrm{PF}_{14}-b$ - $\mathrm{PisO}_{10}$ is not deep enough to keep the charge from returning, and the microphase domain separation is not large. It should be noted that the obtained HOMO levels of $\mathrm{PF}_{14}, \mathrm{PF}_{14}-b$ - $\mathrm{Piso}_{10}, \mathrm{PF}_{14}-b$ - $\mathrm{Piso}_{20}, \mathrm{PF}_{14}-b$-Piso 60 , $\mathrm{PF}_{14}-b$-Piso 100 and $\mathrm{Piso}_{100}$ were $-5.48,-5.55,-5.74,-5.84,-6.06$ and $-6.24 \mathrm{eV}$, respectively. Thus, the energy barrier increased with an 
increase in the Piso block length. Furthermore, the $d$-spacing values of $\mathrm{PF}_{14}$ - $b$-Piso $10, \mathrm{PF}_{14}-b$ - $\mathrm{Piso}_{20}, \mathrm{PF}_{14}-b$ - $\mathrm{Piso}_{60}$ and $\mathrm{PF}_{14}$ - $b$-Piso ${ }_{100}$ were $16.8,20.8,24.4$ and $29.2 \mathrm{~nm}$, respectively. As the Piso block length increased, both the energy barrier and microphase separation domain were enhanced. Thus, the trapped carrier change could not return to the original state and thus remained in the high conducting state, indicating nonvolatile memory characteristics.

The $J-V$ curves obtained from the $\mathrm{PF}_{14}-b$ - $\mathrm{Piso}_{\mathrm{n}}$-based memories, on the other hand, were theoretically fitted to both the OFF and ON states in the negative voltage regions (Figure $6 \mathrm{c}$ and $\mathrm{d}$ and
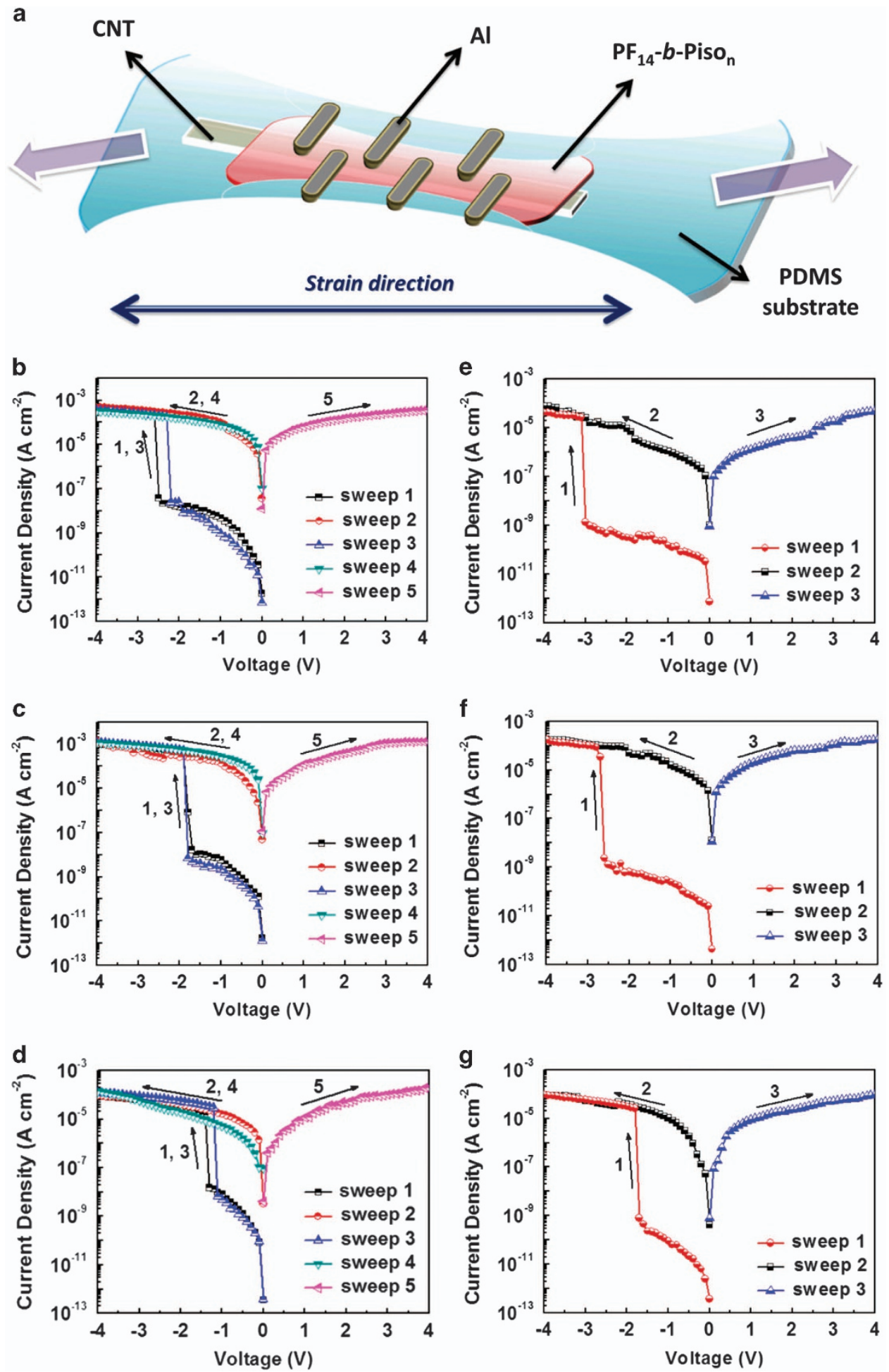

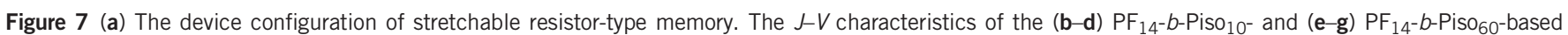
stretchable devices under (b, e) 0, (c, f) 20 and (d, g) 40\% strain. CNT, carbon nanotube; PDMS, poly(dimethylsiloxane); PF, poly[2,7-(9,9-dihexylfluorene)]; Piso, poly(pendent isoindigo). 
Supplementary Figure S11). During the early stages of scanning, the current density increased linearly with the progressive increase in the voltage bias, meaning that the charge transport is governed by the Ohmic contact model. The probed $J-V$ characteristics, nevertheless, were significantly altered under a higher applied bias in the OFF state, and a critical switching point (that is, threshold voltage) between the $\mathrm{ON}$ and OFF states was reached. In this operating region, the $J-V$ curves in the logarithmic plots are linear, with slopes of $\sim 2.18,2.28$, 2.34 and 2.43 for $\mathrm{PF}_{14}-b$ - $\mathrm{Piso}_{10}, \mathrm{PF}_{14}-b$ - $\mathrm{Piso}_{20}, \mathrm{PF}_{14}-b$ - $\mathrm{PisO}_{60}$ and $\mathrm{PF}_{14}-b$-Piso ${ }_{100}$, respectively. It should be noted that a slope greater than 2 indicates that the switching behavior in the OFF state qualitatively matches the trap-associated space-charge-limitedconduction model, ${ }^{33}$ meaning that the holes are injected into the active layer of the memory cell and captured by hole transport/ trapping sites $(\mathrm{PF})$ and then induce several electrons in electron transport/trapping sites (Piso) via a charge transfer interaction. The induced counter space charge near the electrode indeed limits the escape of charge carriers from the trapping sites. In the ON state, the plot of $\log \left(\mathrm{J} \mathrm{V}^{-1}\right)$ versus $\mathrm{V}^{1 / 2}$ showed a linear relationship (inset of Figure $6 c$ and $d$ ), suggesting that the trap-assisted Poole-Frenkel emission mechanism dominated the low-resistance state. The occurrence of Poole-Frenkel emission is likely owing to the charge transport of the $\mathrm{PF}_{14}-b$ - $\mathrm{Piso}_{\mathrm{n}} \mathrm{s}$-filled charge traps to form the trap-free environment. ${ }^{34}$

We demonstrated the formation of a donor-acceptor diblock copolymer system whose resistive switching behaviors can be manipulated for efficient digital information storage. Stretchable memory devices, moreover, were fabricated with volatile SRAM and nonvolatile WORM characteristics using $\mathrm{PF}_{14}-b$ - $\mathrm{Piso}_{10}$ and $\mathrm{PF}_{14}-b$ - $\mathrm{PisO}_{60}$ as the active materials, respectively. The stretchable devices were fabricated through a pre-strain method, ${ }^{22}$ a common technique for generating organic stretchable electronics, including light-emitting diodes, ${ }^{35}$ solar cells, ${ }^{36}$ and memories; ${ }^{22}$ the device configuration is illustrated in Figure $7 \mathrm{a}$. Figure $7 \mathrm{~b}-\mathrm{g}$ and Supplementary Figure S12 show the $J-V$ curves of $\mathrm{PF}_{14^{-}}-b$ - $\mathrm{Piso}_{10^{-}}$and $\mathrm{PF}_{14}$-b-Piso ${ }_{60}$-based stretchable resistive memory devices under tensile strains ranging from 0 to $50 \%$. SRAM and WORM characteristics with well-defined electrical responses could be observed for the $\mathrm{PF}_{14}-b$ - $\mathrm{Piso}_{10}$ and $\mathrm{PF}_{14}-b$ - $\mathrm{Piso}_{60}$ devices, respectively, which are identical to those of devices prepared on an ITO glass substrate. Notably, stable memory behaviors could be obtained with an ON/OFF memory ratio of up to $10^{5}$ at $-1 \mathrm{~V}$, suggesting that our stretchable memories can be stably operated as the active layer is elongated. It should be noted that the threshold voltage of both the $\mathrm{PF}_{14}-b$ - $\mathrm{Piso}_{10^{-}}$and $\mathrm{PF}_{14}-b$-Piso $60^{-}$-based stretchable devices decreased as the tensile strain was increased because the active layer thickness was slightly reduced during stretching.

More importantly, the durability of the programmed memory parameters, such as the ON/OFF current ratio and threshold voltage, under various stretching conditions were investigated (Figure 8 and Supplementary Figure S13). Both the $\mathrm{PF}_{14^{-}}-\mathrm{P}_{-} \mathrm{PisO}_{10^{-}}$and $\mathrm{PF}_{14}$-b-Piso $60^{-}$-based devices were tested under 200 stretch/release cycles at 20 and $40 \%$ applied strain to determine the stability and reproducibility of the stretchable resistive memories. The ON/OFF ratio and threshold voltage of the $\mathrm{PF}_{14}-b$ - $\mathrm{Piso}_{10}$ and $\mathrm{PF}_{14}-b$ - $\mathrm{PisO}_{60}$ stretchable memories decreased slightly during the continuous stretching cycles because the conducting channel in the active layer may have been damaged under strain. Nevertheless, these electrical properties were still comparable to those of the device fabricated on a rigid ITO substrate, indicating the potential of the polymer-based devices for stretchable electronic applications.
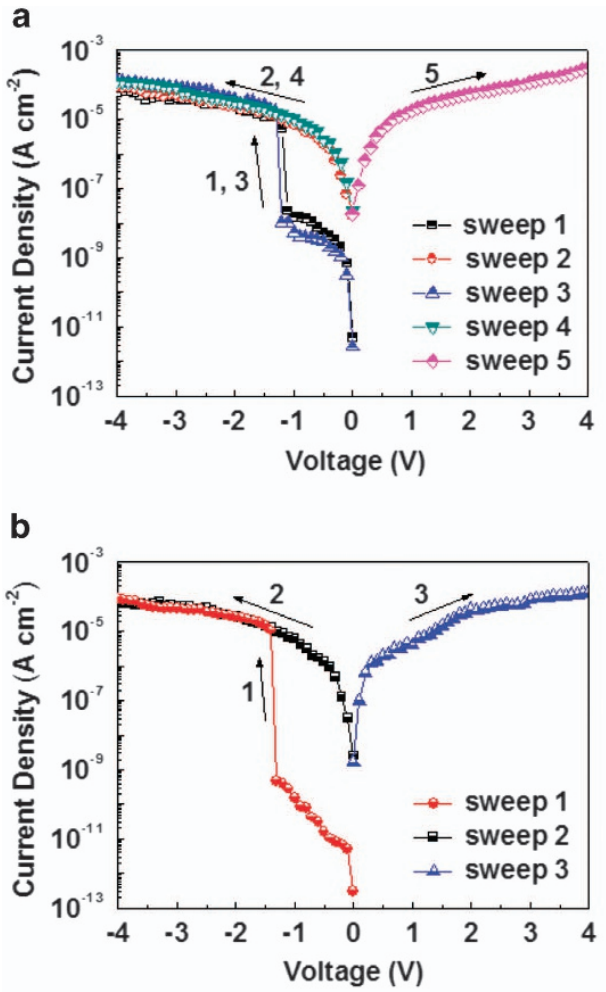

C
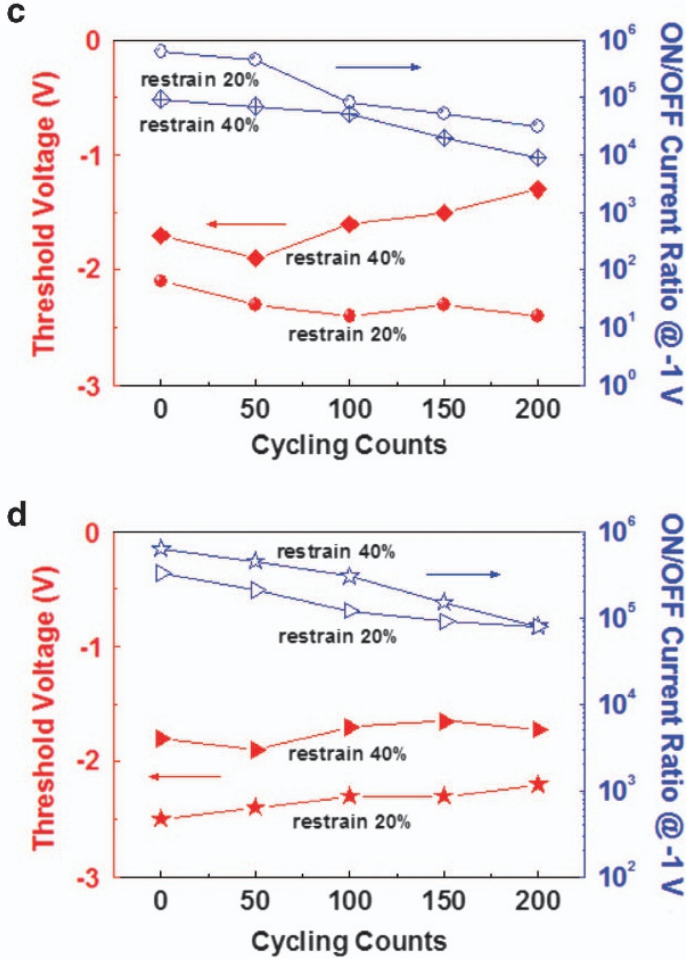

Figure $8 \mathrm{~J}-V$ characteristics of the (a) $\mathrm{PF}_{14}-b$-Piso 10 and (b) $\mathrm{PF}_{14}-b$-Piso 60 stretchable memory devices under $40 \%$ strain after 200 stretch/release cycles. Mechanical endurance of the (c) $\mathrm{PF}_{14}-b$-Piso 10 and (d) $\mathrm{PF}_{14}-b$-Piso 60 stretchable devices. PF, poly[2,7-(9,9-dihexylfluorene)]; Piso, poly(pendent isoindigo).

The changes in the electrical properties of the stretchable memory devices may be related to the thin film morphology of the active layer. Figure 9 and Supplementary Figure S14 show the AFM topographies 


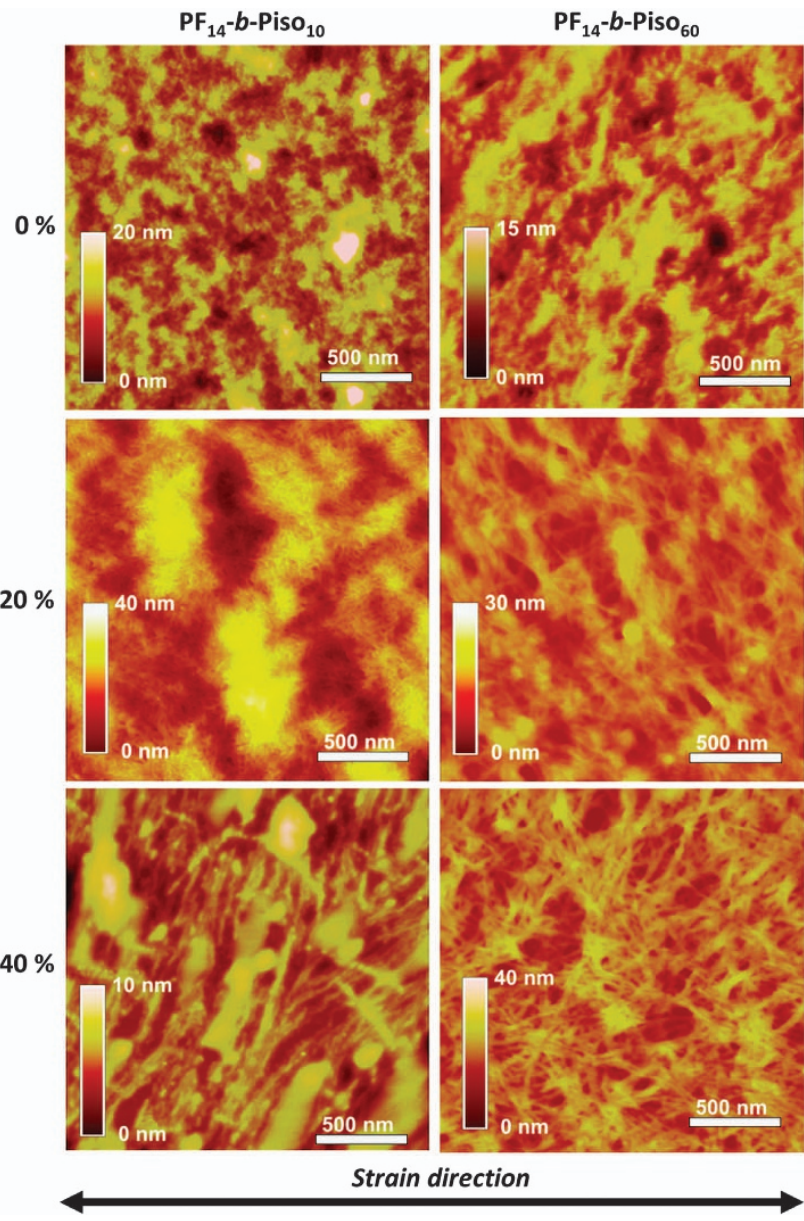

Figure 9 AFM topographies of $\mathrm{PF}_{14}-b$ - $\mathrm{PisO}_{10}$ and $\mathrm{PF}_{14}-b$ - $\mathrm{PisO}_{60}$ thin films on a pre-strained PDMS substrate that was released back to the unstretched state (that is, $0 \%$ ) and then restrained to 20 and $40 \%$, respectively. AFM, atomic force microscopy; PDMS, poly(dimethylsiloxane); PF, poly[2,7(9,9-dihexylfluorene)]; Piso, poly(pendent isoindigo).

of $\mathrm{PF}_{14}-b$ - $\mathrm{Piso}_{10}$ and $\mathrm{PF}_{14}-b$ - $\mathrm{Piso}_{60}$ thin films under strains ranging from 0 to $40 \%$. Generally, no distinct cracking was observed on the surface under strain, explaining why the active layer could maintain its electrical properties under stretching. The formation of the crack-free surface under stretching may have been owing to the protection against buckling afforded by PDMS during the pre-strain treatment (Supplementary Figure S15). ${ }^{22,36}$ Nanostructures self-assembled by the PF rods, however, could not be obtained in the unstretched films (that is, $0 \%$; relax back from pre-strain) of either $\mathrm{PF}_{14}-b$ - $\mathrm{Piso}_{10}$ and $\mathrm{PF}_{14^{-}}-b$ $\mathrm{PisO}_{60}$ because the thin films were relatively compressed. As the tensile strain was applied (that is, 20 or 40\%), nanofibrillar PF channels were clearly observed on the surface, comparable to those formed on the rigid substrate (Figure 3). It should be noted that additional wrinkles perpendicular to the strain direction were observed on the $40 \%$ restrained $\mathrm{PF}_{14}-b$ - $\mathrm{Piso}_{10}$ surface because the soft coil segment composition of $\mathrm{PF}_{14}-b$ - $\mathrm{Piso}_{10}$ was low, reducing its thin film ductility.

\section{CONCLUSIONS}

Conjugated rod-coil diblock copolymers, poly[2,7-(9,9-dihexylfluorene)-block-poly(pendent isoindigo) $\left(\mathrm{PF}_{14}-b\right.$ - $\mathrm{Piso}_{\mathrm{n}}, n=10,20,60$ and 100) consisting of main-chain conjugated PF donors and pendent electron-withdrawing isoindigo were successfully prepared. Tunable surface structures and polymer properties were achieved by controlling the PF/Piso coil-to-rod ratio. Self-assembled fibrillar nanostructures as well as effective charge transport channels in the polymer thin films were formed through the thermal annealing process, leading to stable resistance switching behavior for memory device applications. The studied resistive memories exhibited volatile SRAM $\left(\mathrm{PF}_{14}-b\right.$ - $\left.\mathrm{Piso}_{10}\right)$ and nonvolatile WORM $\left(\mathrm{PF}_{14}-b\right.$ - $\left.\mathrm{PisO}_{20}, 60,100\right)$ characteristics with an ON/OFF ratio of up to $10^{6}$ and a data retention time over $10^{4} \mathrm{~s}$ on the basis of $\mathrm{PF}_{14}-b$-Piso $\mathrm{n}_{\mathrm{n}} \mathrm{s}$ with different lengths of the Piso segment. The results indicate that stable digital information storage electronics could be achieved and the charge storage volatility was easily manipulated by tuning the PF/Piso ratio. More importantly, the memory cells were integrated on a PDMS substrate to make the devices stretchable. Reliable and reproducible electrical characteristics of both SRAM- and WORM-type memory were exhibited under an applied tensile strain ranging from 0 to $50 \%$, demonstrating the potential for high-performance wearable electronic applications.

\section{CONFLICT OF INTEREST}

The authors declare no conflict of interest.

\section{ACKNOWLEDGEMENTS}

We acknowledge financial support from the Ministry of Science and Technology of Taiwan.

1 Ling, Q. D., Liaw, D. J., Zhu, C. X., Chan, D. S. H., Kang, E. T. \& Neoh, K. G. Polymer electronic memories: materials, devices and mechanisms. Prog. Polym. Sci. 33, 917-978 (2008).

2 Heremans, P., Gelinck, G. H., Muller, R., Baeg, K. J., Kim, D. Y. \& Noh, Y. Y. Polymer and organic nonvolatile memory devices. Chem. Mater. 23, 341-358 (2011).

3 Liu, C.-L. \& Chen, W.-C. Donor-acceptor polymers for advanced memory device applications. Polym. Chem. 2, 2169-2174 (2011).

4 Wu, H.-C., Yu, A.-D., Lee, W.-Y., Liu, C.-L. \& Chen, W.-C. A poly (fluorene-thiophene) donor with a tethered phenanthro $[9,10-d]$ imidazole acceptor for flexible nonvolatile flash resistive memory devices. Chem. Commun. 48, 9135-9137 (2012).

5 Hahm, S. G., Kang, N.-G., Kwon, W., Kim, K., Ko, Y.-G., Ahn, S., Kang, B. G., Chang, T., Lee, J. S. \& Ree, M. Programmable bipolar and unipolar nonvolatile memory devices based on poly(2-( $\mathrm{N}$-carbazolyl)ethyl methacrylate) end-capped with fullerene. Adv. Mater. 24, 1062-1066 (2012).

6 Fang, Y.-K., Liu, C.-L., Li, C. X., Lin, C.-J., Mezzenga, R. \& Chen, W.-C. Synthesis, morphology, and properties of poly(3-hexylthiophene)-block-poly(vinylphenyl oxadiazole) donor-acceptor rod-coil block copolymers and their memory device applications. Adv. Funct. Mater. 20, 3012-3024 (2010).

7 Ling, Q. D., Chang, F. C., Song, Y., Zhu, C. X., Liaw, D. J., Chan, D. S. H., Kang, E. T. \& Neoh, K. G. Synthesis and dynamic random access memory behavior of a functional polyimide. J. Am. Chem. Soc. 128, 8732-8733 (2006).

8 Kim, K., Kim, Y. Y., Park, S., Ko, Y.-G., Rho, Y., Kwon, W., Chung, Y. J., Kwon, J. G., Jung, J. T., Kim, E. Y., Kim, K. O., Jang, B., Lee, S. H. \& Yang, C. H. Nanostructureand orientation-controlled digital memory behaviors of linear-brush diblock copolymers in nanoscale thin films. Macromolecules 47, 4397-4407 (2014).

9 Chiu, Y.-C., Liu, C.-L., Lee, W.-Y., Chen, Y., Kakuchi, T. \& Chen, W.-C. Multilevel nonvolatile transistor memories using a star-shaped poly((4-diphenylamino)benzyl methacrylate) gate electret. NPG Asia Mater. 5, e35 (2013).

10 Song, S., Ko, Y.-G., Lee, H., Wi, D., Ree, B. J., Li, Y., Michinobu, T. \& Ree, M. High-performance triazole-containing brush polymers via azide-alkyne click chemistry: a new functional polymer platform for electrical memory devices. NPG Asia Mater. 7, e228 (2015)

11 Ouyang, J. Y., Chu, C. W., Szmanda, C. R., Ma, L. P. \& Yang, Y. Programmable polymer thin film and non-volatile memory device. Nat. Mater. 3, 918-922 (2004).

12 Song, S., Cho, B., Kim, T.-W., Ji, Y., Jo, M., Wang, G., Choe, M., Kahng, Y. H., Hwang, H. \& Lee, T. Three-dimensional integration of organic resistive memory devices. Adv. Mater. 22, 5048-5052 (2010).

13 Zheng, H., Zheng, Y., Liu, N., Ai, N., Wang, Q., Wu, S., Zhou, J., Hu, D., Yu, S., Han, S., Xu, W., Luo, C., Meng, Y., Jiang, Z., Chen, Y., Li, D., Huang, F., Wang, J., Peng, J. \& Cao, Y. All-solution processed polymer light-emitting diode displays. Nat. Commun. 4, 1971 (2013).

14 Zaumseil, J., Donley, C. L., Kim, J. S., Friend, R. H. \& Sirringhaus, H. Efficient top-gate, ambipolar, light-emitting field-effect transistors based on a green-lightemitting polyfluorene. Adv. Mater. 18, 2708-2712 (2006). 
15 Shih, C.-C., Chiu, Y.-C., Lee, W.-Y., Chen, J.-Y. \& Chen, W.-C. Conjugated polymer nanoparticles as nano floating gate electrets for high performance nonvolatile organic transistor memory devices. Adv. Funct. Mater. 25, 1511-1519 (2015).

16 Lian, S.-L., Liu, C.-L. \& Chen, W.-C. Conjugated fluorene based rod-coil block copolymers and their PCBM composites for resistive memory switching devices. ACS Appl. Mater. Interfaces 3, 4504-4511 (2011).

17 Wu, H.-C., Liu, C.-L. \& Chen, W.-C. Donor-acceptor conjugated polymers of arylene vinylene with pendent phenanthro $[9,10-d]$ imidazole for high-performance flexible resistor-type memory applications. Polym. Chem. 4, 5261-5269 (2013).

18 Sekitani, T. \& Someya, T. Stretchable, large-area organic electronics. Adv. Mater. 22, 2228-2246 (2010).

19 Rogers, J. A., Someya, T. \& Huang, Y. Materials and mechanics for stretchable electronics. Science 327, 1603-1607 (2010).

20 Benight, S. J., Wang, C., Tok, J. B. H. \& Bao, Z. Stretchable and self-healing polymers and devices for electronic skin. Prog. Polym. Sci. 38, 1961-1977 (2013).

21 Wu, H.-C., Benight, S. J., Chortos, A., Lee, W.-Y., Mei, J., To, J. W. F., Lu, C., He, M., Tok, J. B.-H., Chen, W.-C. \& Bao, Z. A rapid and facile soft contact lamination method: evaluation of polymer semiconductors for stretchable transistors. Chem. Mater. 26, 4544-4551 (2014).

22 Lai, Y. C., Huang, Y. C., Lin, T. Y., Wang, Y. X., Chang, C. Y., Li, Y. X., Lin, T.-Y., Ye, B.-W., Hsieh, Y.-P., Su, W.-F., Yang, Y.-J. \& Chen, Y.-F. Stretchable organic memory: toward learnable and digitized stretchable electronic applications. NPG Asia Mater. 6, e87 (2014).

23 Ji, Y., Zeigler, D. F., Lee, D. S., Choi, H., Jen, A. K., Ko, H. C. \& Kim, T. W. Flexible and twistable non-volatile memory cell array with all-organic one diode-one resistor architecture. Nat. Commun. 4, 2707 (2013).

24 Song, S., Jang, J., Ji, Y., Park, S., Kim, T.-W., Song, Y., Yoon, M.-H., Ko, H. C., Jung, G.-Y. \& Lee, T. Twistable nonvolatile organic resistive memory devices. Org. Electron. 14, 2087-2092 (2013).

25 Yokoyama, A., Suzuki, H., Kubota, Y., Ohuchi, K., Higashimura, H. \& Yokozawa, T. Chain-growth polymerization for the synthesis of polyfluorene via Suzuki-Miyaura coupling reaction from an externally added initiator unit. J. Am. Chem. Soc. 129, 7236-7237 (2007).

26 Elmalem, E., Kiriy, A. \& Huck, W. T. S. Chain-growth Suzuki polymerization of n-type fluorene copolymers. Macromolecules 44, 9057-9061 (2011).

27 Matyjaszewski, K. \& Xia, J. Atom transfer radical polymerization. Chem. Rev. 101, 2921-2990 (2001).

28 Chiu, Y.-C., Chen, Y., Kuo, C.-C., Tung, S.-H., Kakuchi, T. \& Chen, W.-C. Synthesis, morphology, and sensory applications of multifunctional rod-coil-coil triblock copolymers and their electrospun nanofibers. ACS Appl. Mater. Interfaces 4, 3387-3395 (2012).
29 Saito, K., Isono, T., Sun, H.-S., Kakuchi, T., Chen, W.-C. \& Satoh, T. Rod-coil type miktoarm star copolymers consisting of polyfluorene and polylactide: precise synthesis and structure-morphology relationship. Polym. Chem. 6, 6959-6972 (2015).

30 Wang, J.-T., Takashima, S., Wu, H.-C., Chiu, Y.-C., Chen, Y., Isono, T., Kakuchi, Y., Satoh, T. \& Chen, W.-C. Donor-acceptor poly(3-hexylthiophene)-block-pendent poly (isoindigo) with dual roles of charge transporting and storage layer for high-performance transistor-type memory application. Adv. Funct. Mater. 26, 2695-2705 (2016).

31 Serin, J. M., Brousmiche, D. W. \& Frechet, J. M. J. A FRET-based ultraviolet to near-infrared frequency converter. J. Am. Chem. Soc. 124, 11848-11849 (2002).

32 Wu, H.-C., Zhang, J., Bo, Z. \& Chen, W.-C. Well-defined star-shaped donor-acceptor conjugated molecules for organic resistive memory devices. Chem. Commun. 51, 14179-14182 (2015).

33 Shang, D. S., Wang, Q., Chen, L. D., Dong, R., Li, X. M. \& Zhang, W. Q. Effect of carrier trapping on the hysteretic current-voltage characteristics in $\mathrm{Ag} / \mathrm{La}_{0.7} \mathrm{Ca}_{0.3} \mathrm{MnO}_{3} / \mathrm{Pt}$ heterostructures. Phys. Rev. B: Condens. Matter Mater. Phys. 73, 245427 (2006).

34 Miao, S., Li, H., Xu, Q., Li, Y., Ji, S., Li, N., Wang, L., Zheng, J. \& Lu, J. Tailoring of molecular planarity to reduce charge injection barrier for high-performance smallmolecule-based ternary memory device with low threshold voltage. Adv. Mater. 24, 6210-6215 (2012).

35 Sekitani, T., Nakajima, H., Maeda, H., Fukushima, T., Aida, T., Hata, K. \& Someya, T. Stretchable active-matrix organic light-emitting diode display using printable elastic conductors. Nat. Mater. 8, 494-499 (2009).

36 Lipomi, D. J., Tee, B. C.-K., Vosgueritchian, M. \& Bao, Z. Stretchable organic solar cells. Adv. Mater. 23, 1771-1775 (2011).

(c) (i) This work is licensed under a Creative Commons Attribution 4.0 International License. The images or other third party material in this article are included in the article's Creative Commons license, unless indicated otherwise in the credit line; if the material is not included under the Creative Commons license, users will need to obtain permission from the license holder to reproduce the material. To view a copy of this license, visit http:// creativecommons.org/licenses/by/4.0/

(C) The Author(s) 2016

Supplementary Information accompanies the paper on the NPG Asia Materials website (http://www.nature.com/am) 